\title{
Mechanical Testing of Poly Hydroxy Butyrate Co Valerate and Natural Fiber by Varying Fiber Length
}

\author{
M. Selwin, N. Rajini
}

\begin{abstract}
The knowledge of $3 D$ printing material used in $3 D$ printing technique is so abundant. Even though there are many critical issues in practical applications. This paper reports the mechanical properties of Environmental friendly Bio composites. This composite material is intended to be used as a replacement for the current $3 D$ printing material. The composite was prepared in compression molding technique under $150 \mathrm{~kg} / \mathrm{cm} 2$ pressure. The composite consists of Poly Hydroxy Butyrate co Valerate (PHBV) and Sansevieria Roxburghiana. The tensile strength of the given specimen is found to be increased by the change in the volume fraction of fibers. Initially composite plates composed of both PHBV and Sansevieria Roxburghiana are prepared with different weight percentage of $\mathrm{PHBV}$ and different lengths of fiber such as $20 \mathrm{~mm}, 30 \mathrm{~mm}, 40 \mathrm{~mm}$ and $50 \mathrm{~mm}$.
\end{abstract}

Keywords: Environmental friendly Bio composites, Poly Hydroxy Butyrate co Valerate (PHBV), Sansevieria Roxburghiana, Compression molding.

\section{INTRODUCTION}

A for both neat PHBV and wood PHBV composites of $10 \%$, $20 \%, 30 \%, 40 \%$ wood content were examined by Luigi-Jules Vandi, Clement Matthew Chan. [2] The diffusive turning of PHBV filaments which were spun from arrangement utilizing a scope of polymer fixations, turn speed and spinneret to gatherer separates by Sarah J Upson. [3] The effect of using a combination of substrates on the synthesis of PHBV which indicates that PHBV was synthesized only when fructose was used as the sole carbon source by Asieh Aramvash. [4] Selective laser sintering was developed for fabricating interconnected porous biodegradable PHBV scaffolds with large surface area and relative porosities upto $80 \%$ by Sven H. Diermanna. [5] Demonstrating the interest of preparing PHBV/PBS blends and the possibility to control their structure and thermal properties by compatibilization with PHBV-g-MA by Salima Kennouche. [6] The impact of mixing and the expansion of little measure of $\mathrm{TiO} 2$ nanoparticles on the dynamic mechanical properties of PLA/PHBV mixes by J.P. Mofokeng A.S. Luyt B.

Revised Manuscript Received on December 29, 2019.

M. Selwin*, Department of Mechanical Engineering, KARE, Krishnankoil, India. Email: selwin123@gmail.com

N. Rajini, Department of Mechanical Engineering, KARE, Krishnankoil, India. Email: rajiniklu@gmail.com
[7] Biodegradable curcumin-stacked electrospun PHBV nanofibers were acquired with imperfection free morphology and their normal distances across extended from $207 \pm 56$ to $519 \pm 15 \mathrm{~nm}$ by Gozde Mutlu. [8] PHBV films with dynamic fundamental oil mixes were exceptionally compelling against L. innocua and E.coli in vitro tests, yet they were significantly less viable in the genuine sustenance tried, except for the impact against $\mathrm{E}$. coli in cheddar tests covered with PHBV- EU or PHBV-CLO films by Raquel Requena.[9] The impacts of g-illumination on PHBV/PLA: $50 / 50 \mathrm{w} / \mathrm{w}$ mixes brought about solid adjustments in the substance structure, particularly after $100 \mathrm{kGy}$ of assimilated portion by Idris Zembouai. [10] Responsive expulsion convention for blending PHBV-g-GMA with a high GMA joining rate and few side responses by Ting Zheng.

\section{MATERIALS}

A. Properties of Poly Hydroxy Butyrate Co Valerate PHBV is obtained from bacteria which is biodegradable, nontoxic and bio compatible. It is very brittle in nature. It possess low elongation. The impact resistance of PHBV is also very low. When disposed it degrades into carbon dioxide and water. PHBV just like fats to humans it is the energy source to micro-organism. Enzymes produced by them degrades it and are consumed. The thermal stability of PHBV is very low with primitive mechanical properties. It has very high processing difficulties.

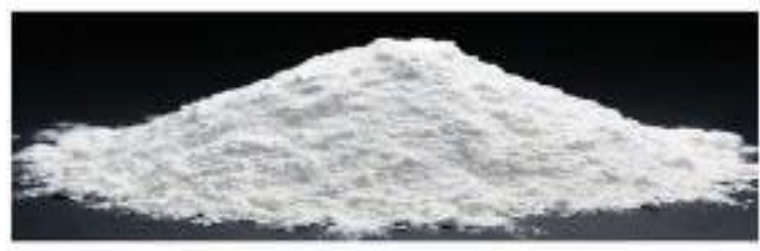

Fig.1. Extracted Sansevieria

\section{B. Properties of Sansevieria Roxburghiana}

The warm conductivity of the fiber diminishes with the expansion of fiber content. The expansion of Sansevieria decreases the Heat Release Rate. At the point when consumed it discharges more carbon dioxide than pitch composite.

The rigidity of Sansevieria fiber is 2.55 occasions more prominent than gum and the effect quality is 4.2 occasions more prominent than the pitch. Elasticity of composite is expanded by $18.16 \%, 36.49 \%, 102.97 \%$, and $155.24 \%$ over virgin polyester at $0.12,0.21,0.28,0.36$ volume division of filaments individually. 


\section{PROBLEM DEFINITION}

The previous material which is utilized in the $3 \mathrm{D}$ printing strategy is for the most part made out of a material which is a standout amongst the most boundless biomass-based, biodegradable (compostable) and biocompatible polymers. It is water-insoluble, can be either straightforward or semistraightforward relying upon polymer crystallinity, and optically dynamic. The primary downsides of the material are high fragility, moderate crystallization rate, and high penetrability to gases. The ways for beating these issues are to utilize plasticizers, copolymerization with different segments, making composites, and mixing with different polymers. So in order to find out an alternative to the pre-existing 3D printing material, a new composite has to be prepared which overcome its defects. Therefore a composite consisting of both Sansevieria Roxburghiana and Poly Hydroxy Butyrate co Valerate (PHBV) is to be prepared. PHBV also possess the properties of brittleness and low impact resistance and the tensile strength of composite increased with the change in the volume fraction of fibers. Apart from this, to decrease the utilization of cost of the printing material and also to reduce the toxicity in the pre-existing material, this composite of PHBV and Sansevieria Roxburghiana will be more needful. Thus a biodegradable replacement can be made thereby reducing all the environmental impacts that the previous materials has incurred. Thus it can be opted as a better replacement in order to eliminate all the health hazards. It can also be considered as a cost effective when compared to the currently using material as it composed of both PHBV and Sansevieria fiber which accounts for the low production cost if the composite plate. Thus it eliminates all the drawbacks of the currently used material.

\section{METHODOLOGY}

The fabrication and mechanical testing PLA and Sansevieria based composite specimen is done by the methodology given

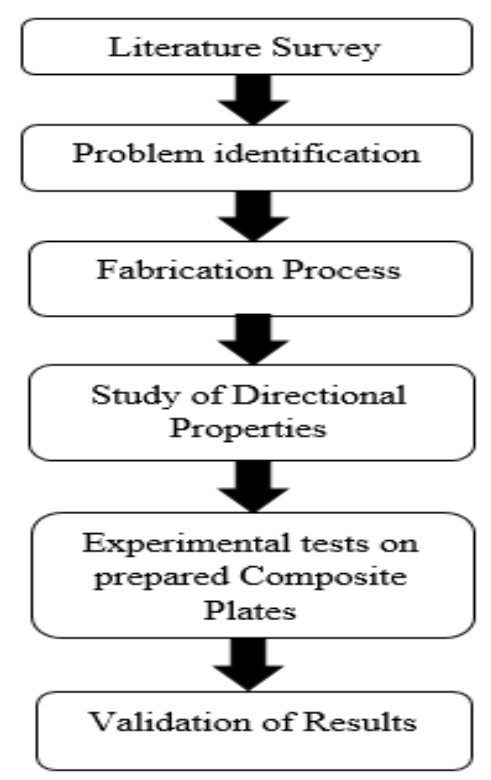

Fig.2. Methodology

\section{PROCESS OF FABRICATION}

\section{A. Compression Molding}

It is a shut form composite that utilizes coordinated metal molds with the use of outside weight. In this strategy a composite layup is set in the open form depression, the shape is shut and drive is connected. The weight stays in the form all through the cycle, which generally happens in a broiler. In this way a composite part with low void substance and high fiber volume portion is created with the mix of warmth and weight. It frequently yields composite parts that have the ideal mechanical properties conceivable from the specific mix of constituent materials.

\section{B. Fiber Preparation}

Initially Sansevieria fiber is prepared to be cut on different lengths such as $20 \mathrm{~mm}, 30 \mathrm{~mm}, 40 \mathrm{~mm}, 50 \mathrm{~mm}$. Pure fiber is separated which does not contain green shades left over. Moreover, fine hair like structured fibers are separated in order to ensure that there are no thick pieces of fiber. This is done because such fibers can leads to improper plate preparation. The separated hair like fine fibers are eventually cut into different lengths.

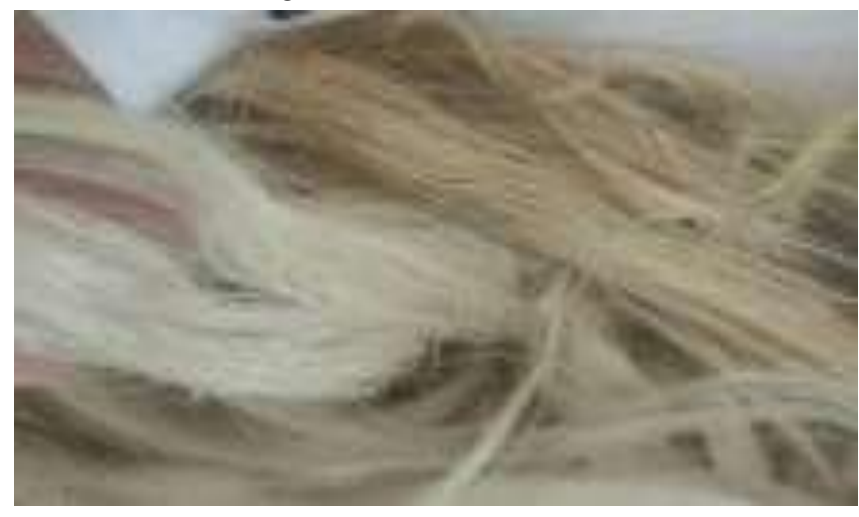

Fig. 3. Extracted Sansevieria

\section{Composite Standards}

Table. 1 Specimen details

\begin{tabular}{|c|c|c|c|}
\hline Standard & $\begin{array}{c}\text { Specification } \\
(\mathbf{m m})\end{array}$ & Test & $\begin{array}{l}\text { Fiber Length } \\
(\mathbf{m m})\end{array}$ \\
\hline ASTM D638 & $165 * 13 * 3$ & Tensile & \multirow{3}{*}{$20,30,40,50$} \\
\hline $\begin{array}{l}\text { ASTM D790- } \\
92 \\
\end{array}$ & $127 * 13 * 3$ & Flexural & \\
\hline ASTM D256 & $60 * 13 * 3$ & Impact & \\
\hline
\end{tabular}

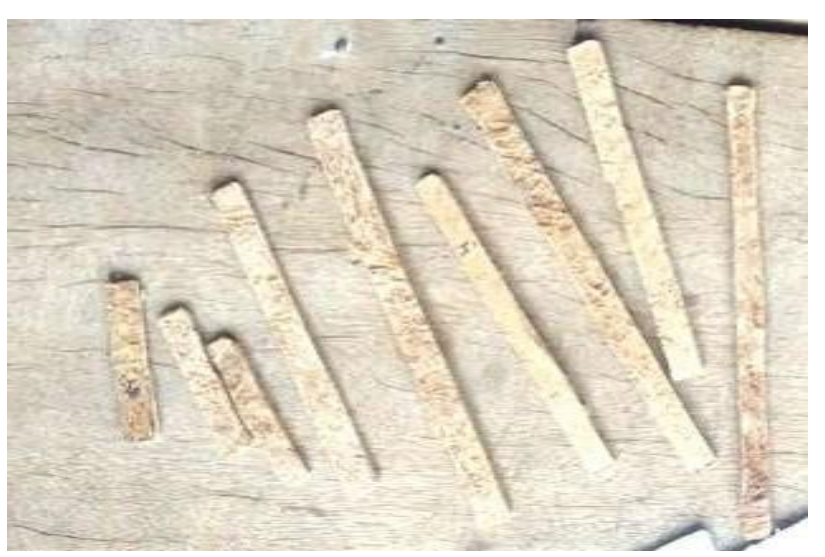

Fig.4. Specimen Preparation 


\section{RESULTS}

The test results are plotted on graph having $\mathrm{X}$-axis as sample number and the $\mathrm{Y}$-axis parameter is taken as strength obtained in each test results in $\mathrm{N} / \mathrm{mm} 2$. Three specimen for each testing gives twelve results in total. The average of the results is calculated and it is considered for the final conclusion. Thus the results are obtained and are plotted in the form of a graph which helps in providing a clear knowledge on the outcome of the results. The following table 2 consists of the list of results obtained from the appropriate test samples with PHBV with fibers of varying length.

Table 2. Test Results

\begin{tabular}{|c|c|c|c|c|c|}
\hline S.no & $\begin{array}{c}\text { Test } \\
\text { parameters }\end{array}$ & $\mathbf{2 0 m m}$ & $\mathbf{3 0 m m}$ & $\mathbf{4 0 m m}$ & $\mathbf{5 0 m m}$ \\
\hline 1 & $\begin{array}{c}\text { Tensile } \\
\text { Strength, } \\
\text { N/mm }\end{array}$ & 18.65 & 11.65 & 14.07 & 14.22 \\
\hline 2 & $\begin{array}{c}\text { Flexural } \\
\text { Strength, } \\
\text { N/mm }\end{array}$ & 33.42 & 35.68 & 39.46 & 39.22 \\
\hline 3 & $\begin{array}{c}\text { Impact, } \\
\text { Joules }\end{array}$ & 3.4 & 2.5 & 2.5 & 2.8 \\
\hline
\end{tabular}

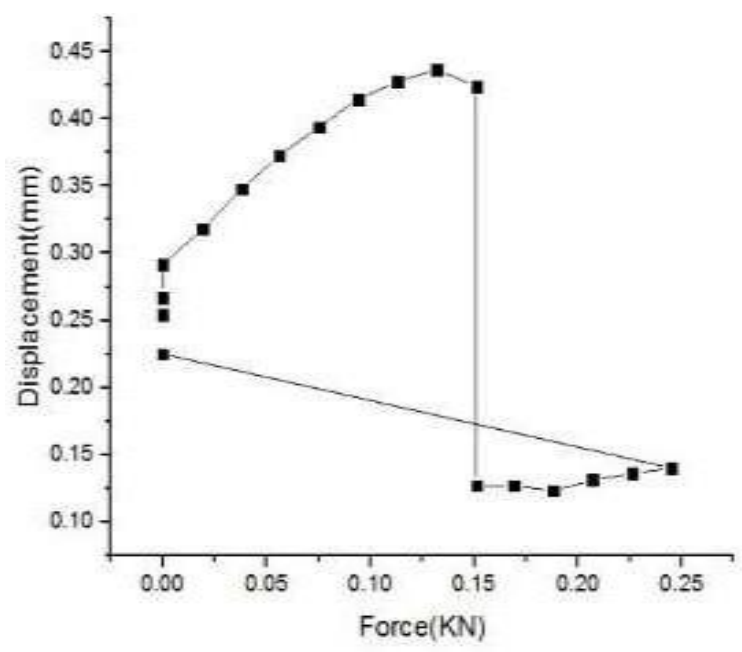

Fig.5. Load vs Displacement (20mm)

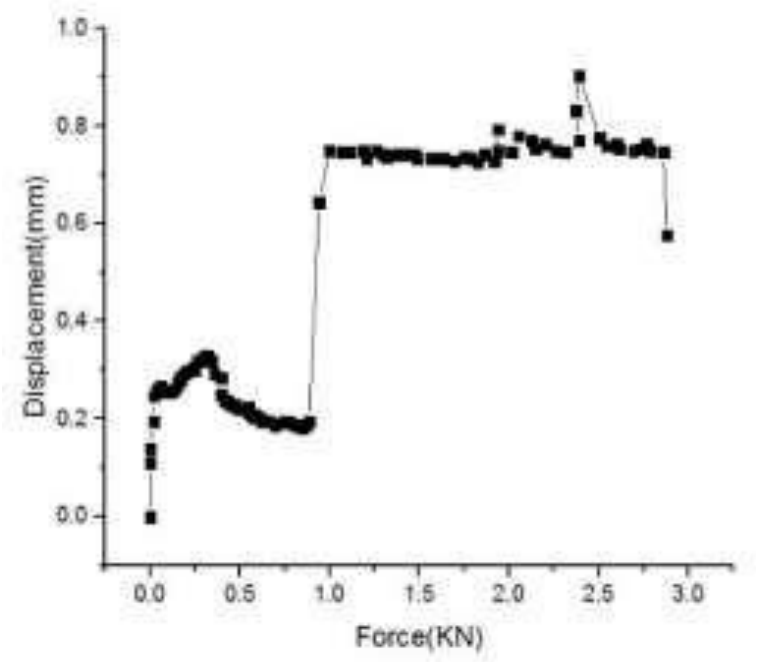

Fig.6. Load vs Displacement (30mm)

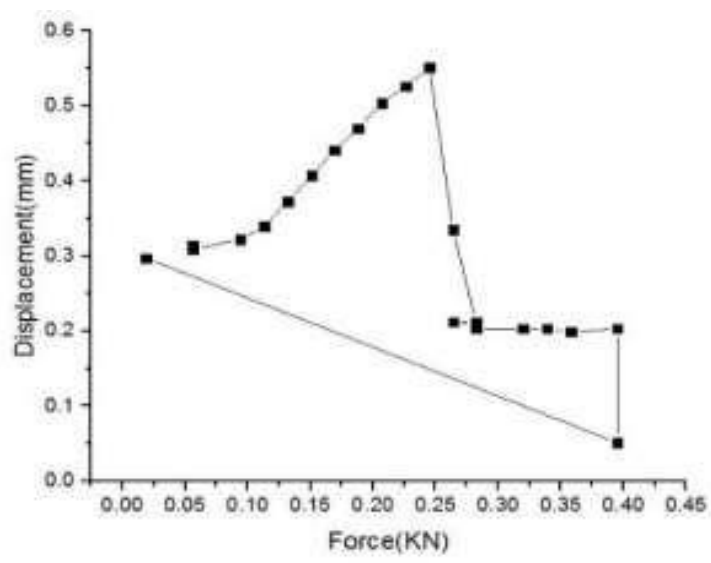

Fig.7. Load vs Displacement (40mm)

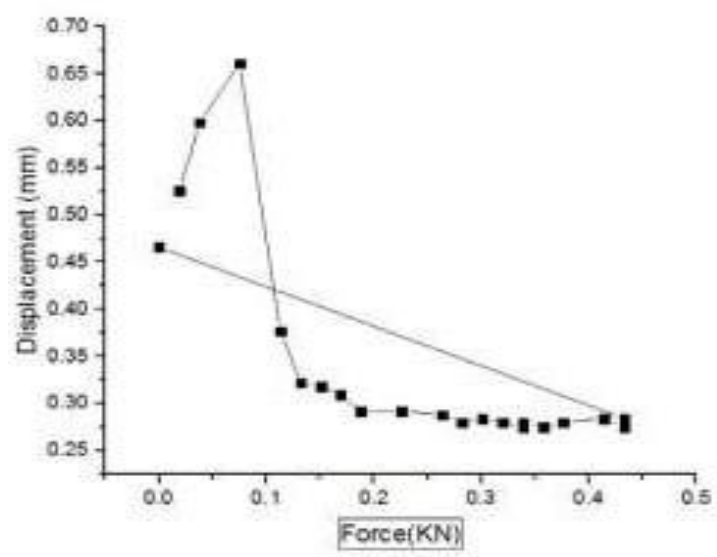

Fig.8. Load vs Displacement (50mm)

\section{CONCLUSION}

This study focuses on utilizing Sansevieria Roxburghiana fiber and Poly hydroxyl butyrate co- Valerate powder as reinforcement towards producing bio degradable composites, thus bringing economic values to the Sansevieria Roxburghiana fiber. Composite plates of different length variation were prepared and the results shows that the sample with $20 \mathrm{~mm}$ fiber has the highest tensile strength when compared to $30 \mathrm{~mm}, 40 \mathrm{~mm}$ and $50 \mathrm{~mm}$ samples. Similarly, $40 \mathrm{~mm}$ and $50 \mathrm{~mm}$ plates contain high flexural strength and eventually $20 \mathrm{~mm}$ sample contain high impact strength than the remaining samples.

\section{REFERENCES}

1. Luigi-Jules Vandi, Clement Matthew Chan, Alan Werker, "Mechanical properties of poly (3-hydroxybutyrate-co3-hydroxyvalerate)/wood flour composites: Effect of interface modifiers", Journal of Applied polymer science (2018), DOI: 10.1002/APP.46828.

2. Sarah J Upson, Tom O'Haire, Stephen J. Russell, "Centrifugally spun PHBV micro and nanofibres", Journal on Material Science and Engineering C (2017), vol. 76, pp.190-195

3. Asieh Aramvash, Samira Hajizadeh-Turchi, Fatemeh Moazzenizavareh, "An Environmentally Friendly and Efficient Method Extraction of PHB Biopolymer with Non-Halogenated Solvents", Journal of Microbial Biotechnology (2015), Vol.25-11, pp.1936-1943. 
4. Sven H. Diermanna, Mingyuan Lua, Yitian Zhaoa, "Synthesis, microstructure, and mechanical behaviour of a unique porous PHBV scaffold manufactured using selective laser sintering", Journal of the Mechanical Behavior of Biomedical Materials (2018), vol 84, pp. 51160 .

5. Salima Kennouche, Nicolas Le Moigne, Mustapha Kaci, "Morphological characterization and thermal properties of compatibilized poly

(3-hydroxybutyrate-co-3- hydroxyvalerate)(PHBV)/ poly (butylene-succinate) (PBS) /halloysite ternary nano composites", European Polymer Journal (2016), vol.75, pp. 142-162

6. Mofokeng, J. P., \& Luyt, A. S, "Dynamic mechanical properties of PLA/PHBV, PLA/PCL, PHBV/PCL blends and their nanocomposites with TiO2 as nanofiller.Zx", Thermochimica acta (2015), vol. 613, pp. 41-53.

7. Gozde Mutlu, Semih Calamak, Kezban Ulubayram, Eylem Guven, "Curcumin-loaded electrospun PHBV nanofibers as potential wounddressing material", Journal of Drug Delivery Science and Technology (2018), vol. 43, pp. 185-193

8. Raquel Requena, María Vargas, Amparo Chiralt, "Eugenol and carvacrol migration from PHBV films and antibacterial action in different food matrices", Journal of Food Chemistry (2019), vol. 277, pp. 38-45.

9. Idris Zembouai, Mustapha Kaci, Stephane Bruzaud, "Gamma irradiation effects on morphology and properties of PHBV/PLA blends in presence of compatibilizer and Cloisite 30B", Polymer Testing (2016), vol. 49, pp.29-37.

10. Ting Zheng, Zhan Zhang, Srishti Shukla, "PHBV-graft-GMA via reactive extrusion and its use in PHBV/nanocellulose crystal composites", Carbohydrate Polymers (2019), vol.205, 1, pp. 27-34

\section{AUTHORS PROFILE}

Mr. M. Selwin, have completed his M.E in Manufacturing Engineering. His area of research is Natural Composites. $\mathrm{He}$ is currently working as an

Assistant Professor in the Department of Mechanical Engineering in Kalasalingam Academy of Research and Education

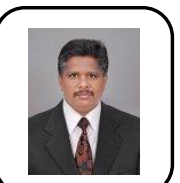

Dr. N. Rajini, is a Professor in Kalasalingam Academy of Research and Education. His area of Research is Bio Composites. His Citation is 1320 , h index is 19 and i10 index is 32 . He is doing his project in Bio composites. He have several research collaborations with foreign countries. 